\title{
Enabling roll-processed and flexible Organic Solar Cells based on PffBT4T through temperature-controlled slot-die coating.
}

Fernández Castro, Marcial; Rodríguez, Moisés Espíndola; Stanzani, Edoardo; Sørensen, Michael Korning; Yun, Shinhee; Andreasen, Jens Wenzel

Published in:

IEEE Journal of Photovoltaics

Link to article, DOI:

10.1109/JPHOTOV.2021.3136784

Publication date:

2022

Document Version

Peer reviewed version

Link back to DTU Orbit

Citation (APA):

Fernández Castro, M., Rodríguez, M. E., Stanzani, E., Sørensen, M. K., Yun, S., \& Andreasen, J. W. (2022). Enabling roll-processed and flexible Organic Solar Cells based on PffBT4T through temperature-controlled slotdie coating. IEEE Journal of Photovoltaics, 12(2), 602-610. https://doi.org/10.1109/JPHOTOV.2021.3136784

\section{General rights}

Copyright and moral rights for the publications made accessible in the public portal are retained by the authors and/or other copyright owners and it is a condition of accessing publications that users recognise and abide by the legal requirements associated with these rights.

- Users may download and print one copy of any publication from the public portal for the purpose of private study or research.

- You may not further distribute the material or use it for any profit-making activity or commercial gain

- You may freely distribute the URL identifying the publication in the public portal 


\title{
Enabling roll-processed and flexible Organic Solar Cells based on PffBT4T through temperature-controlled slot-die coating.
}

\author{
Marcial Fernández-Castro, Moisés Espíndola-Rodríguez, Edoardo Stanzani, Michael Korning \\ Sørensen, Shinhee Yun and Jens Wenzel Andreasen*.
}

\begin{abstract}
Although the mark of $18 \%$ power conversion efficiency (PCE) was surpassed recently, organic solar cells (OSCs) still have several challenges to overcome in order to fully compete with silicon-based solar cells in the energy market. One of the main challenges is upscaling of the technology. Despite the recent advances in PCEs, a big scalability gap still exists between the best lab-scale device and large-scale modules fabricated via roll-to-roll process. The polymer donor PffBT4T- $\mathrm{C}_{9} \mathrm{C}_{13}$ has already shown efficiencies of almost $12 \%$ together with PCBM. Combined with the NFA O-IDTBR, a reduced voltage loss of 0.5 $\mathrm{V}$ between the optical band gap and $V_{O C}$ is obtained, with an opencircuit voltage up to $1.12 \mathrm{~V}$, which is one of the highest values reported for OSCs. In this work, we demonstrate a route to upscaling OSCs based on PffBT4T-C ${ }_{9} \mathrm{C}_{13}$ :O-IDTBR through temperature-controlled slot-die coating, solving the challenges of the temperature dependent aggregation (TDA) behavior, which strongly affects the efficiency of the device. Efficiencies above $4 \%$ were achieved in our flexible and roll-processed devices with an area of $\sim 1 \mathrm{~cm} 2$ and the different origins of the scalability lag were studied. As an additional necessary step for scalability, we incorporate the use of a hydrocarbon-based solvent to remove the environmentally dangerous halogenated solvents. To the best of our knowledge, this is the first work reporting PffBT4T:O-IDTBR solar cells fabricated in open air using slot-die coating in a rollplatform with flexible substrates, that mimics large-scale roll-toroll processing.
\end{abstract}

Index Terms - hydrocarbon, flexible devices, organic solar cells, roll-to-roll, scalable fabrication, slot-die coating, non-fullerene

\section{INTRODUCTION}

$\mathrm{O}^{\mathrm{s}}$ RGANIC SOLAR CELLS (OSCS) have shown notable progress in recent years, achieving over $18 \%$ power conversion efficiency (PCE) and showing their potential as a firm candidate for several applications [1]. OSCs present several advantages, such as the benefit of a really short energy payback time and high manufacturing speeds using large-scale roll-to-roll processing [2]. However, most record efficiencies are reported using non-scalable fabrication techniques and under conditions that are currently not feasible to reproduce in a big factory, for example a glove box [3]. The fast increase of OSCs performance in recent years is mainly due to the development of new non-fullerene acceptors (NFAs), which can be modified through molecular design to fine-tune their absorption spectrum and energy levels. One NFA is the small molecule IDTBR, whose molecular structure is shown in Fig. 1. IDTBR is a so-called Acceptor-Donor-Acceptor (ADA) NFA, first developed by McCulloch et al, with either a linear noctyl (O-IDTBR) or a branched 2-ethylhexyl (EH-IDTBR) side chain [4]. This structure leads to a strong intra-chain charge transfer between the donor-acceptor moieties, leads to a higher absorbance and a narrower bandgap than fullerenes. Blended with different donor polymers, this small molecule has demonstrated efficiencies above $10 \%$. One of them is the lowbandgap, high-performance donor polymer PffBT4T, which together with EH-IDTBR has shown efficiencies up to $11.1 \%$ when processed from hydrocarbon solvents [5]. It is important to mention that the processability using this type of solvent (instead of halogenated solvents) is an important step towards the scalability of OSCs, as they are more environmentally friendly and can be easily obtained from petroleum. With the same material combination, a PCE of $9.1 \%$ has been achieved in devices with a thick active layer of $300 \mathrm{~nm}$, which is desirable for easy processing when scaling up [6]. Another advantage of this material combination that leads to better photovoltaic performance is the voltage loss reduction achieved by decreasing the energy offsets, which leads to open-circuit voltages above $1 \mathrm{~V}$ with this material combination [7]. The socalled "burn-in" degradation is an initial loss of PV performance that happens within the first hours when the solar cells are placed under sunlight and is present in a wide range of OSCs. Remarkably, OSCs based in PffBT4T:IDTBR have shown a negligible "burn-in" effect for glass encapsulated devices [8]. It has been shown that 4-bromoanisole as a solvent additive can improve the performance of devices based on $\mathrm{O}$ IDTBR [9], due to a better solubility of the acceptor, which might also enhance the morphology of the blend [10]. All these advantages suggest this material combination as a firm candidate to scale up in order to compete at an industrial level. When only considering devices fabricated using scalable fabrication techniques, the record efficiency of this combination drops to above $8 \%$ [11]. However, to the best of our knowledge, there are not reported OSCs based on PffBT4T fabricated using roll-processing slot-die coating on flexible substrates. It is worth mentioning that flexibility is still one of the most desirable properties for OSCs, due to the wide range of new applications this brings to the technology, such as building-integrated photovoltaics or wearable electronics [12]. One of the main challenges this material combination presents 
when up-scaling to slot-die coating is that PffBT4T- $\mathrm{C}_{9} \mathrm{C}_{13}$ has strong Temperature Dependent Aggregation (TDA) behaviour [13]. This means that the polymer aggregates in solution below a certain temperature threshold that depends on the solution concentration, the solvent, additives, and acceptor used. Therefore, a certain temperature needs to be maintained through all the slot-die coating set up in order to avoid aggregation of the ink in the syringe, tubes, and slot-die coating head. This factor can be seen as adverse because the slot-die coating is much more challenging, but it can also be used to our benefit by optimizing the aggregation states through drying kinetics. Successful results were obtained to fabricate hot slot-die coated PM6:Y6 OSCs, whose polymer donor is also a TDA [14]. In the field of Organic transistors, slot-die coating is also used as a scalable deposition technique [15], [16]. The materials normally used in the field do not suffer from TDA, but this work opens the possibility to investigate slot-die coating of TDA materials for different applications.

In this work, we report the fabrication and optimization of hot slot-die coated PffBT4T-C ${ }_{9} \mathrm{C}_{13}$ :O-IDTBR solar cells, using roll-processing on flexible substrates. The specific alkyl chain length $\left(\mathrm{C}_{9} \mathrm{C}_{13}\right)$ promotes an optimal balance between face-on orientation and domain purity and size when processed from hydrocarbon solvents, leading to efficiencies above $11 \%$ when blended with a fullerene acceptor [17].

This work aims to enable roll-processed PffBT4T- $\mathrm{C}_{9} \mathrm{C}_{13}$ :OIDTBR and study the main challenges towards the full scalability of this material combination to a full roll-to-roll platform. To overcome the issues caused by the aggregation behaviour, an improved version of our previously reported layer-by-layer optimization approach was developed [10], implementing temperature control not only in the head but also through all the circuit (syringe and tubes), demonstrating the universality of this method to optimize NFA-based systems in a roll-platform using hot slot-die coating. Due to the need of using $\mathrm{MoO}_{3}$ hole transport layer in the configuration of our devices, evaporation steps were added. It has been demonstrated the possibility of a hybrid roll-to-roll fabrication including vacuum steps [18], but improving solution-processed interfacial layers should still be a priority for upscaling. Efficiencies up to $4.0 \%$ PCE, $52.3 \% \mathrm{FF}$, and open-circuit voltages above $1 \mathrm{~V}$ were achieved on $0.8 \mathrm{~cm}^{2}$ devices in this work. A scalability study was also performed in order to study the main reasons for the scalability lag between roll-processed devices and spin-coating lab-scale devices. When using shadow masks of reduced areas, better results were achieved, mainly due to the improved series resistance and fill factor. 4.6\% PCE was achieved with a FF of $57.9 \%$ when a mask of $0.085 \mathrm{~cm}^{2}$ aperture area was used.

\section{EXPERIMENTAL SECTION}

\section{A. Materials}

All the materials involved in this study were used as purchased without any further purification. PffBT4T- $\mathrm{C}_{9} \mathrm{C}_{13}$ was purchased from Ossila materials (Batch M2083A4) whereas OIDTBR was purchased from 1-Material Inc. The chemical structure of both materials is shown in Fig. 1. All the solvents and the Zinc Oxide nanoparticle ink (Helios'Ink H-SZ01034) are from Sigma Aldrich Inc. The ITO-coated flexible substrate was purchased from FOM Technologies and it is composed of a PET substrate and an ITO layer with a sheet resistance of 63 $\Omega /$ square (Fig. S4, SI)

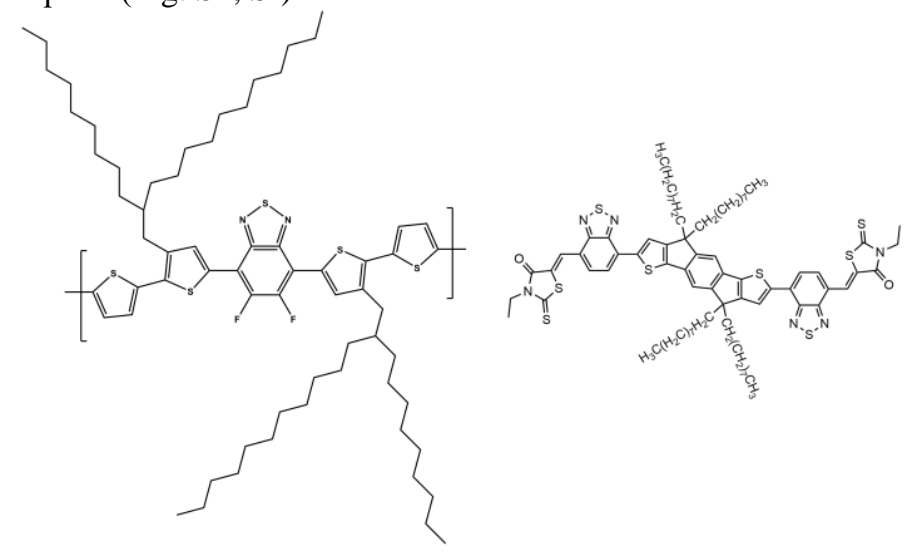

Fig. 1. Chemical structures of PffBT4T- $\mathrm{C}_{9} \mathrm{C}_{13}$ (left) and O-IDTBR (right).

\section{B. Device fabrication}

A mini roll-coater (FOM Technologies), composed of a rotating wheel and a coating head, was used for slot-die coating the active layer. This equipment provides a direct comparison to a regular roll-to-roll equipment. With this equipment, substrate temperature and speed can be easily controlled. The head-to-substrate distance is adjustable and was always kept constant at around $1 \mathrm{~mm}$. The coating of the active layer was done under open-air conditions.
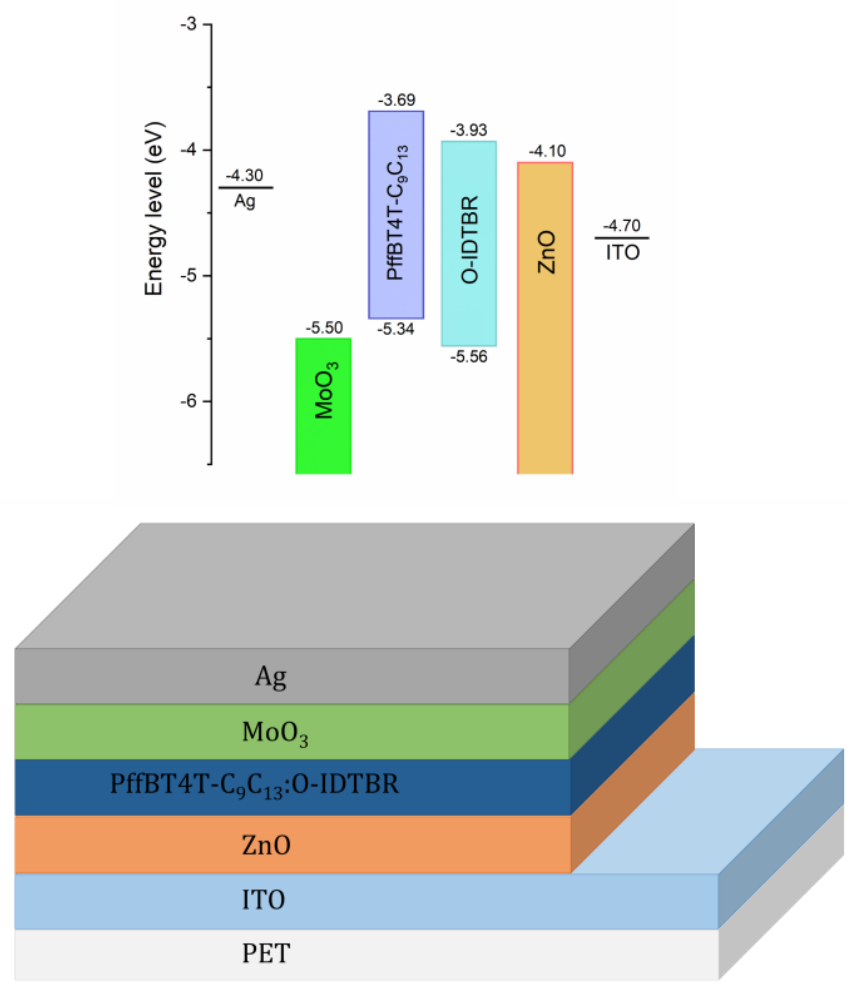

Fig. 2. Schematic representation of the energy levels for the different layers of the fabricated and optimized devices (up) and the layer stack (down). 
Unless stated otherwise, mesitylene was used as the solvent, with $2.5 \% \mathrm{v} / \mathrm{v}$ 4-bromoanisole as additive. The donor/acceptor ratio of PffBT4T- $\mathrm{C}_{9} \mathrm{C}_{13}$ :O-IDTBR was kept at $1: 1$ to prepare the ink that was dissolved at $90{ }^{\circ} \mathrm{C}$ and stirred overnight.

All devices in this work have the following inverted architecture: PET/ITO/Active Layer/MoO $/$ /Ag. A schematic representation of the energy levels is shown in Fig. 2 [19], [20].

One meter of ITO-coated PET is placed on the roll-coater rotating wheel, where substrate temperature is set up to $75^{\circ} \mathrm{C}$. After that, the $\mathrm{ZnO}$ ink is slot-die coated at a speed of $12 \mathrm{~mm} / \mathrm{s}$ and then annealed in air in an oven at $100{ }^{\circ} \mathrm{C}$ for $10 \mathrm{~min}$ before being placed again on the roll-coater.

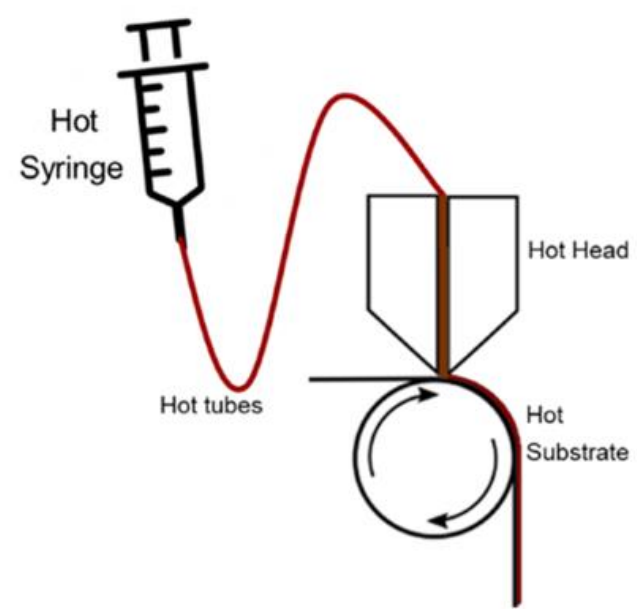

Fig. 3. Schematic representation of our temperature-controlled slot die coating.

Following the findings of our previous optimization procedure different temperatures were chosen simultaneously on the head and the rotating wheel [10]. The temperature of the ink in the syringe was kept slightly higher $\left(+5{ }^{\circ} \mathrm{C}\right)$ than the head-substrate temperatures to make sure that the ink was always completely liquid, whereas the heating tube temperature matched the one on the head. The range of tested temperatures was $60{ }^{\circ} \mathrm{C}, 80^{\circ} \mathrm{C}$ and $100{ }^{\circ} \mathrm{C}$, with $60^{\circ} \mathrm{C}$ as the limit before the aggregation starts at the working concentration $(20 \mathrm{mg} / \mathrm{ml})$. All temperatures are independently controlled $\left( \pm 1{ }^{\circ} \mathrm{C}\right)$.

The active layer was then slot-die coated on top of the $\mathrm{ZnO}$ layer, with a coating speed of $0.6 \mathrm{~m} / \mathrm{min}$ and a flow rate of 0.06 $\mathrm{mL} / \mathrm{min}$. The film thickness was measured by AFM on slot-die coated films from inks with different total concentrations (20, 25 , and $30 \mathrm{mg} / \mathrm{ml}$ ).

Twelve different positions among the stripe are selected to ensure homogeneity and placed in a metal evaporator. $10 \mathrm{~nm}$ of $\mathrm{MoO}_{3}$ (Kurt J. Lesker, Molybdenum Oxide Pieces $99.5 \%$ pure) are deposited at $0.2 \AA / \mathrm{s}$ using a shadow mask with a base pressure of $2 \times 10^{-5} \mathrm{mbar}$, then $150 \mathrm{~nm}$ of $\mathrm{Ag}$ are thermally evaporated at a rate of $1.5 \AA / s$. The materials were evaporated from tungsten boats and an INFICON XTM/2 system was used to monitor the deposition rate and thickness.

The encapsulation of the final devices was made using a homemade EPOXY glue based on bisphenol A diglycidyl ether and Chissonox 221 monomers. The procedure consists in placing the devices between two glass slides and EPOXY-based glue on both sides. After that, the final encapsulated devices are cured under UV light for 3 minutes. This encapsulation is made to protect the devices from external agents, increasing their stability. As a final step, short annealing of 45 seconds in a hot plate at $120^{\circ} \mathrm{C}$ was performed, as the $\mathrm{FF}$ of the cells was highly improved when devices were annealed, despite a slight loss of short circuit current.

All the device fabrication and manipulation steps were done under open-air conditions, with the exception of the vacuum deposition carried out for the HTL and the back electrode.

\section{Characterization}

J-V curves were measured with an in-lab Solar Simulator with AM 1.5G spectrum and 1 Sun intensity using a Xenon lamp as the light source. The calibration at 1 Sun intensity was done with a certified monocrystalline $\mathrm{Si}$ reference cell. A Keithley 2400 Source meter was used for JV data acquisition using $25 \mathrm{mV}$ steps.

Stability measurements were performed under the same light source at $25{ }^{\circ} \mathrm{C}$ controlled device temperature. JV curves acquired every 20 minutes.

External Quantum Efficiency (EQE) and transmittance were measured using a QEX10 system (PV Measurements Inc.) from $300 \mathrm{~nm}$ to $900 \mathrm{~nm}$ (5 nm step size) calibrated with a $\mathrm{Si}$ photodiode.

The sheet resistance was measured with a 4-point probe (Guardian Manufacturing) acquired with a Keithley 2401 source meter.

The thickness and roughness of the $\mathrm{MoO}_{3}$ hole transport layer were characterized using Spectroscopic ellipsometry. This allowed calibration of the INFICOM XTM/2 system to have layers with a precise thickness.

For the GIWAXS and GISAXS measurements, a laboratory $\mathrm{Cu} \mathrm{K} \mathrm{K}_{\alpha}$ source with the wavelength of $1.5418 \AA$ was used to probe the films at an incidence angle of $0.18^{\circ}$. Scattering data were acquired with 2.5 hour exposure time on an EIGER-4M detector $110 \mathrm{~mm}$ and $2500 \mathrm{~mm}$ from the sample. The equipment used is a Xeuss 3.0 from Xenocs S.A.

The surface morphology and thickness of the active layer were characterized at room temperature using scanning probe microscopy (DME, DualScope ${ }^{\mathrm{TM}}$ scanner DS 95-50 with a DualScope $^{\mathrm{TM}}$ controller C-26) with PtIr5-coated Si tips (NanoWorld, PointProbe EFM). The spring constant of the tip is $\sim 5 \mathrm{~N} / \mathrm{m}$, and the curvature radius is below $10 \mathrm{~nm}$.

\section{RESULTS AND DISCUSSION}

Nowadays, it is still unknown how every external parameter, such as coating temperature, speed, or chosen solvent, affects the morphology and crystallinity of a bulk heterojunction. Therefore, optimizing them through manipulating the drying kinetics of the active layer during the coating is a critical step for the fabrication of the OSC devices, as morphology and PV performance are highly related [21]. Following our previously reported optimization procedure [10], we screened chlorobenzene (CB), o-xylene (o-Xy), and mesitylene (Mes) solvents (Fig. S1, SI). As expected from previously reported 
studies, PffBT4T dissolved in the hydrocarbon-based solvent mesitylene showed the best performing devices [5]. Hydrocarbon solvents are more environmentally friendly than halogenated solvents, and they are easily obtained from petroleum, making them a more suitable choice for OSC fabrication. We obtained a Power Conversion Efficiency (PCE) and Fill Factor (FF) of $2.04 \%$ and $45.5 \%$ for CB, $2.54 \%$, and $43 \%$ for o-Xy and $3.61 \%$ and $45.0 \%$ for Mes (Table S1, SI). The Open circuit voltage $\left(\mathrm{V}_{\mathrm{OC}}\right)$ was around $1 \mathrm{~V}$ in all cases. With mesitylene, the additives 4-bromoanisole (BrA), 1,8diiodooctane (DIO), and 1-phenylnaphthalene (PN) additives were tested. $2.5 \% \mathrm{BrA}$ showed the highest average efficiencies of $3.64 \pm 0.18 \%$ (Fig. S2, SI) and higher homogeneity between the parameters of the solar cells (Table S2, SI). This result confirms BrA as a firm candidate to enhance morphology of OIDTBR based solar cells, as the same trend was observed when paired with P3HT as the donor [9], [10].

As stated in the Experimental section, all the final devices were annealed at $120{ }^{\circ} \mathrm{C}$ after encapsulation. Despite losing some current, annealing improved the overall PCE and FF, suggesting an improvement in active layer morphology that leads to a lower recombination mechanism taking place. That can be deduced from the increased shunt resistance of annealed devices (Fig. S3, SI). Thermal annealing as post-deposition treatment is known to cause improved crystallinity in several fullerene and non-fullerene organic solar cells [22]. It has also been demonstrated, in the case of P3HT, that post-deposition annealing can lead to a change in the alignment of the donor, inducing edge-on orientation in the bulk and face-on donor-rich phases at the interfaces [23].

\section{A. Optimization procedure}

As the first step of our sequential optimization, temperatures were varied and controlled simultaneously in the substrate, head, and ink circuit. Fig. 4a shows the J-V curves of the best device obtained for each tested temperature. Fig. 4a-inset shows the statistical data of the PCE evolution. Each box shows the first to the third quartile, the median is indicated as a horizontal line and the average value as a square. Solar cells fabricated at $60{ }^{\circ} \mathrm{C}$ show the highest spread in the data whereas the solar cells slot die coated at $100^{\circ} \mathrm{C}$ were measured to be very similar to each other as seen in Fig. 4a-inset and Table I. The optimal temperature for hot-slot die coating PffBT4T- $\mathrm{C}_{9} \mathrm{C}_{13}$ :O-IDTBR was found to be $80{ }^{\circ} \mathrm{C}$, with a maximum PCE of $4.04 \%$ and a maximum $\mathrm{FF}$ of $52.3 \%$. The average values of the representative parameters of the solar cells (Table I) coated at be $80^{\circ} \mathrm{C}$ are also found to be above the average of the solar cells coated at $60^{\circ} \mathrm{C}$ or $100^{\circ} \mathrm{C}$. The devices coated at be $80^{\circ} \mathrm{C}$ also showed an incredibly high open-circuit voltage $\left(\mathrm{V}_{\mathrm{OC}}\right)$ above 1 $\mathrm{V}$, which is among the highest reported for OSCs [7].

As the next step, with an optimal temperature of $80^{\circ} \mathrm{C}$ in the tube, head, and substrate, the thickness was also optimized choosing a range of suitable values. Despite that thin layers can lead to better performance in small lab-scale devices, [24] this is not the case for flexible roll-processed active layers, for several reasons. First, extremely thin layers are too fragile in flexible substrates. That means that bending the devices leads
TABLE I

PV PARAMETERS OF SIX FABRICATED DEVICES WITH DIFFERENT SUBSTRATE-HEAD TEMPERATURES WITH A TOTAL SOLUTION CONCENTRATION OF $20 \mathrm{MG} / \mathrm{ML}$.

\begin{tabular}{lccc}
\hline \hline PV Parameter & \multirow{2}{*}{$60{ }^{\circ} \mathrm{C}$} & $80{ }^{\circ} \mathrm{C}$ & $100{ }^{\circ} \mathrm{C}$ \\
\hline $\mathrm{PCE}_{\max }(\%)$ & 3.36 & 4.04 & 2.35 \\
$\mathrm{FF}_{\max }(\%)$ & 48.2 & 52.3 & 51.1 \\
$P C E(\%)$ & $2.91 \pm 0.28$ & $3.69 \pm 0.27$ & $2.18 \pm 0,15^{*}$ \\
$F F(\%)$ & $43.5 \pm 3.1$ & $50.8 \pm 1.4$ & $47.2 \pm 3.5$ \\
$J_{s c}\left(\mathrm{~mA} / \mathrm{cm}^{2}\right)$ & $6.87 \pm 0.12$ & $7.35 \pm 0.49$ & $4.79 \pm 0.17$ \\
$J_{s c-E Q E}$ & 6.92 & 7.80 & 4.18 \\
$\left(\mathrm{~mA} / \mathrm{cm}^{2}\right)$ & $0.98 \pm 0.01$ & $1.01 \pm 0.01$ & $0.97 \pm 0.01$ \\
$\mathrm{~V}_{\text {oc }}(\mathrm{V})$ & &
\end{tabular}

to cracks in the active layer, leading to shunts that decrease the performance and even short-circuiting the full device. Second, when considering full-printed devices, usually flexographic printing is chosen for the back electrode in roll-to-roll manufacturing [25]. This technique applies a certain pressure to the layer stack that is needed for printing, thus increasing the probability of cracking or damaging the layers underneath. In our case, the best performing devices were found at around 220 $\mathrm{nm}$ thickness, with an average PCE of $3.69 \%$ and a maximum PCE of $4.04 \%$. The average and maximum values of all the relevant PV parameters are shown in Table II.

TABLE II

PV PARAMETERS OF SIX DEVICES FABRICATED WITH SLOT DIE HEAD AND SUBSTRATE TEMPERATURE OF $80^{\circ} \mathrm{C}$ AND DIFFERENT ACTIVE LAYER THICKNESS

\begin{tabular}{lccc}
\hline \hline PV Parameter & $220 \mathrm{~nm}$ & $250 \mathrm{~nm}$ & $270 \mathrm{~nm}$ \\
\hline $\mathrm{PCE}_{\max }(\%)$ & 4.04 & 3.30 & 3.45 \\
$\mathrm{FF}_{\max }(\%)$ & 52.3 & 49.5 & 49.0 \\
$P C E(\%)$ & $3.69 \pm 0.27$ & $3.18 \pm 0.09$ & $3.32 \pm 0.10$ \\
$F F(\%)$ & $50.8 \pm 1.4$ & $48.2 \pm 0.9$ & $47.6 \pm 1.6$ \\
$J_{s c}\left(m A / \mathrm{cm}^{2}\right)$ & $7.35 \pm 0.49$ & $6.53 \pm 0.23$ & $6.96 \pm 0.26$ \\
$J_{s c-E Q E}$ & 7.80 & 6.76 & 6.93 \\
$\left(m A / c m^{2}\right)$ & $1.01 \pm 0.01$ & $1.00 \pm 0.01$ & $1.01 \pm 0.01$ \\
$\mathrm{~V}_{\mathrm{oc}}(\mathrm{V})$ & & & \\
& & &
\end{tabular}

One of the reasons why efficiency is not higher is the low FF presented in all devices, with $52.3 \%$ achieved as the maximum, which can be mainly attributed to the ITO-coated PET substrates that have a high sheet resistance (Fig. S4, SI). The high sheet resistance causes a high series resistance in our largearea devices. Additionally, the current in the devices is low, with $7.96 \mathrm{~mA} / \mathrm{cm}^{2}$ as the highest. Our active layers are coated in atmospheric lab conditions, and therefore exposed to humidity, oxygen, and dust at several steps during the fabrication procedure. Around half an hour passes during the manipulation of samples after coating the active layer, and before the evaporation step. Another 30-60 min pass with the full devices in open-air conditions before encapsulation.

Improving the performance of the transparent front electrode in flexible devices without compromising the cost or the transparency is still a necessary step to improve the efficiency of roll-coated devices. The low current is one of the key factors keeping the efficiency of our flexible PffBT4T-C ${ }_{9} \mathrm{C}_{13}$ halved compared to other PffBT4T-based devices reported for labscale devices on ITO glass [7]. 
The large thickness of our slot-die coated devices may be another detrimental factor for the current generation. It has been shown that for PBDB-TF:IT-4F based devices, the short circuit current drastically drops from 20.2 to $12.4 \mathrm{~mA} / \mathrm{cm}^{2}$ when increasing the AL thickness from $100 \mathrm{~nm}$ to $1000 \mathrm{~nm}$. In the same work, it is also demonstrated that thickness variations lead to different behaviours for each material combination [26].

Not shown here, a test of devices with a layer thickness of $150 \mathrm{~nm}$ was done, and they were not robust enough to survive the post-fabrication manipulation, encapsulation, and annealing procedures. When going to thicker layers, up to $270 \mathrm{~nm}$, the devices showed poorer performance. Therefore, the maximum PCE was found at the lowest possible thickness that did not compromise the robustness of the active layer to be suitable for large-area flexible devices. A thinner layer may help to reduce recombination due to long charge carrier pathways, as it is known that the charge recombination probability increases in thicker OSCs due to the longer distance that the free carriers have to diffuse before being collected [24]. The effect of the active layer thickness in the J-V curves does not seem as severe as the effect of the changes induced by temperature (Fig. 4).
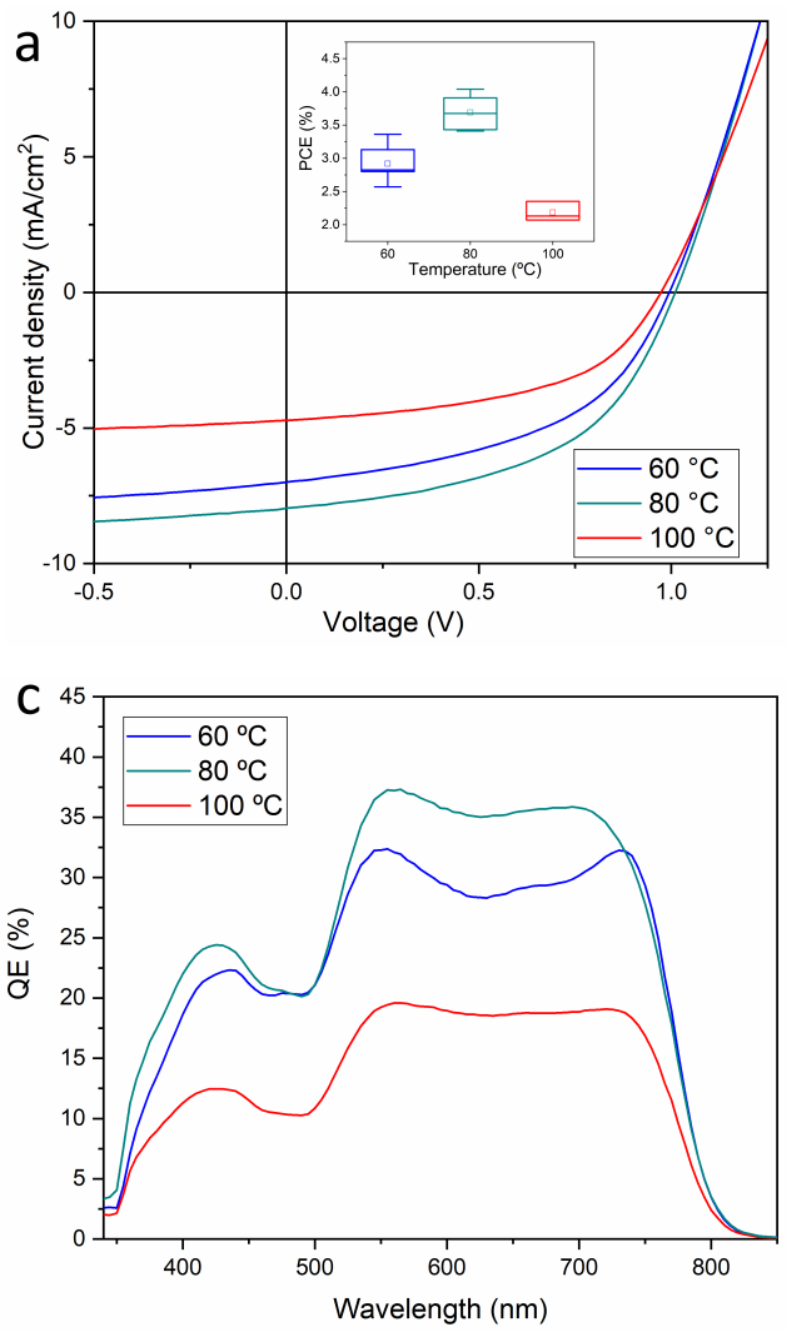

External Quantum Efficiency (EQE) measurements were done to investigate the spectral photocurrent generation. The contribution of the acceptor has its maximum at longer wavelengths $(690 \mathrm{~nm})$, whereas donor PffBT4T has two main peaks (630 and $695 \mathrm{~nm}$ ), as can be seen in Fig. 5. Both materials also display secondary absorption peaks at $450 \mathrm{~nm}$ (donor) and $400 \mathrm{~nm}$ (acceptor) (Fig. 5). This absorption property gives this material combination a dark blue color, which can be taken into consideration for building integration applications. The primary peaks of the donor and acceptor are close between them, enhancing the quantum efficiency of the blend in this specific region, whereas the secondary ones are contributing to photocurrent generation in the region around 400-500 nm (shorter wavelengths). Therefore, this material combination is a good match in terms of spectral properties. The maximum EQE was obtained by the devices fabricated at $80{ }^{\circ} \mathrm{C}$, as can be seen in Fig. 4c, with a measured $J_{\text {SC-EQE }}$ of $7.80 \mathrm{~mA} / \mathrm{cm}^{2}$, in good agreement with the one-sun $\mathrm{J}_{\mathrm{SC}}$. The optimized device shows a broad photon-to-current response from both materials in the blend. When the active layer is thicker than $220 \mathrm{~nm}$, the
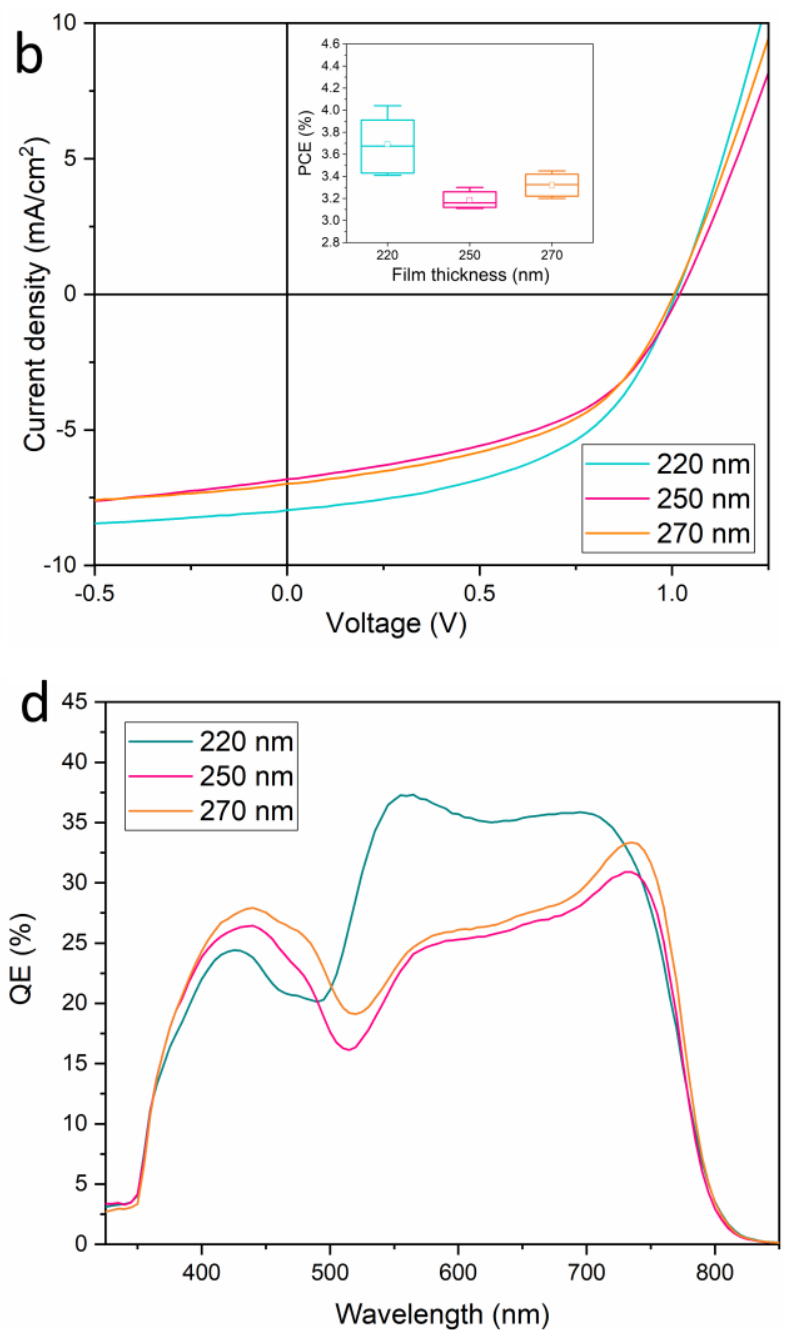

Fig. 4. J-V curves of devices fabricated with different a) ink-head-substrate temperatures with a fixed thickness of 220 nm, b) active layer thickness with inkhead-substrate at $80^{\circ} \mathrm{C}$. Insets in a-b display PCE statistics of six fabricated devices respectively. External Quantum Efficiency measurements of representative devices are shown for c) temperature variations and d) thickness variations. 
contribution of the blend to the photocurrent is decreased (Fig. $4 d)$.

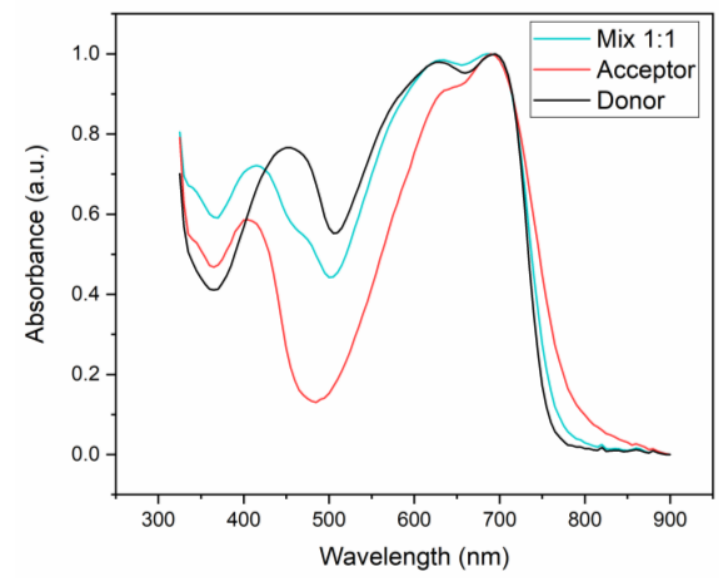

Fig. 5. Normalized absorbance of slot-die coated layers of Donor (of PffBT4T$\mathrm{C}_{9} \mathrm{C}_{13}$ ), Acceptor (O-IDTBR), and the mixture of both of them (1:1 ratio).

To probe the charge recombination behaviour in the devices, the light intensity $\left(\mathrm{P}_{\text {light }}\right)$ dependence of the short-circuit current was examined. $\mathrm{J}_{\mathrm{SC}}$ usually follows the power-law dependence Jsc $\alpha \mathrm{P}_{\text {in }}{ }^{\mathrm{S}}$, the linear dependence of $\mathrm{J}_{\mathrm{SC}}$ with light intensity $(\mathrm{S} \approx$ 1) suggests weak or no second-order recombination while $S<$ 1 suggests charge transport limited behaviour [27], [28]. Figure S6a, SI shows that $\mathrm{S}$ is equal to $0.949,0.915$, and 0.918 for solar cells with AL with 220,250 , and $270 \mathrm{~nm}$ in thickness. It indicates that the photocurrent losses in the thicker AL are due to second-order bimolecular charge recombination. We also find that our devices suffer additional trap-assisted recombination losses as we observe a strong dependence of $\mathrm{V}_{\mathrm{OC}}$ on $\mathrm{P}_{\text {in }}$ (Fig S6b, SI). From the plot of $\mathrm{V}_{\mathrm{OC}}$ versus $\ln \left(\mathrm{P}_{\mathrm{in}}\right)$ it is possible to get information on the extent of second-order recombination (slope $=\mathrm{kT} / \mathrm{q}$ ) or trap-assisted recombination (slope > kT/q), where k, T, and q refer to the Boltzmann constant, temperature, and unitary charge, respectively [27], [29]. The slope values from the $220 \mathrm{~nm}$ and $250 \mathrm{~nm}$ active layers were determined to be $3.78 \mathrm{kT} / \mathrm{q}$ and $5.14 \mathrm{kT} / \mathrm{q}$, which indicates that the thicker layers have more pronounced trapassisted recombination losses. Additionally, from grazing incidence wide and small angle X-ray scattering (Figure S7 and $\mathrm{S} 8, \mathrm{SI})$, it is evident that the thinnest film has considerably less edge-on material (Table S4, SI). Moreover, for the thicker films the donor/acceptor domain sizes are considerably larger (Table S5, SI). The morphological differences may impact the likelihood of recombination and thus the amount of material that contributes to the photocurrent [28]. It has been shown that morphological changes, such as phase separation, can be induced by concentration variations in similar OSCs [30]. As our thicker films are made from higher concentration solutions, these morphological changes could be the reason for the reduced photocurrent and lower performance of the thicker $\mathrm{AL}$ devices.

It is worth noting that the thickness modification for the thicker layers is smaller $(20 \mathrm{~nm})$, thus the $\mathrm{J}-\mathrm{V}$ curves and the EQEs are expected to have more similarities between them than for the thinner case.

A clear redshift is seen after annealing (Fig. S3, SI), showing an increase in the photovoltaic band gap of the solar cells and probably indicating higher crystallinity of the blend. [31] However, there is also a loss in quantum efficiency and photocurrent, thus a compromise in the annealing time is necessary to find the optimal point where the PCE is maximum. In our case, this was found at $120^{\circ} \mathrm{C}$ for 45 seconds (Table S3).

\section{B. Surface morphology characterization}

To obtain the surface morphologies of PffBT4T- $\mathrm{C}_{9} \mathrm{C}_{13}$ :OIDTBR layers for the different film deposition temperatures, we performed atomic force microscopic (AFM) measurements at room temperature (Fig. 6). In the AFM image of a film deposited at $60^{\circ} \mathrm{C}$, which is the lowest temperature among the three samples, the aggregation is observed on the surface with the grain-size of $\sim 500 \mathrm{~nm}$ (Fig. 6a). Consequently, its rootmean-square roughness $(\mathrm{Sq})$ is higher than the other samples with a value of $\sim 15 \mathrm{~nm}$. This is probably related to the TDAbehaviour of the donor. As $60{ }^{\circ} \mathrm{C}$ is really close to the aggregation limit at the working concentration of the solution (below $\mathrm{T}=55^{\circ} \mathrm{C}$, the solution is completely aggregated), the polymer aggregates quickly during deposition thus forming a grain-like surface, which is detrimental for the device efficiency. For the samples deposited at higher temperatures, such as $80^{\circ} \mathrm{C}$ or $100^{\circ} \mathrm{C}$, the surface morphology becomes smoother with smaller and fewer aggregates (Fig. $6 \mathrm{~b}$ and c). We can conclude that higher drying temperature avoids the polymer aggregation and induces a smoother surface (Fig. 6d). a

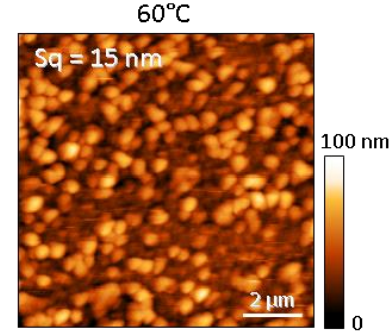

c

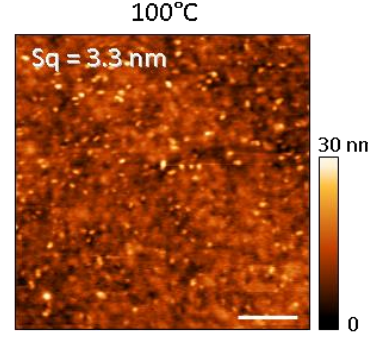

b

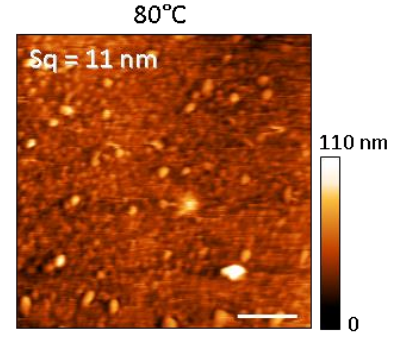

d

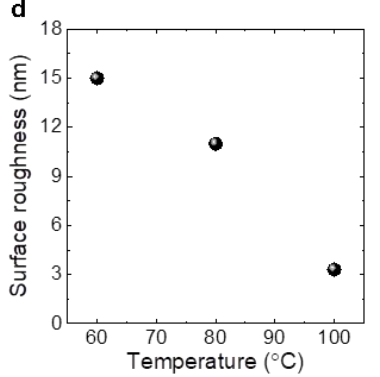

Fig. 6. Deposition temperature dependent surface morphology and roughness of the roll-processed PffBT4T- $\mathrm{C}_{9} \mathrm{C}_{13}$ :O-IDTBR active layers. Representative AFM images of the layers coated at a. $60^{\circ} \mathrm{C}, \mathrm{b} .80^{\circ} \mathrm{C}$, and c. $100^{\circ} \mathrm{C}$ with a same scale bar of $2 \mu \mathrm{m}$ (white line). The RMS roughness (Sq) is represented in each image. d. Surface roughness vs. temperature obtained from $a, b$, and c.

For the thickness characterization with a variation of the solution concentration, we scratched the layers and obtained the AFM images near the scratches, in which the substrate is exposed (the top images in Fig. S5a-d, SI). By acquiring the thicknesses from the step-like cross-sections near the edges, we are able to demonstrate that the layer thickness increases linearly with the concentration of the solution, as expected from Equation 1 (the bottom graphs of Fig. S5a-d and Fig. S9, SI). 
Using this linear fitting, it would be possible to estimate the necessary concentration for a desired thickness layer.

$$
\text { Thickness }=\frac{c f}{r v w} \text { (Eq. 1) }
$$

Where $f$ is the ink flow, $w$ is the width of the film, $v$ the coating speed, and $\rho$ the density of the materials in film.

\section{Scalability}

As proof of the scalability issues that this system presents, an average device was chosen to study the effect on the PV performance when using shadow masks with different aperture areas (Table III). The PCE of the cell is reduced by $18.5 \%$ when comparing the smallest aperture area measured $\left(0.085 \mathrm{~cm}^{2}\right)$ to the largest $\left(0.75 \mathrm{~cm}^{2}\right)$. J-V curves of the devices with different aperture areas are shown in Fig. 7.
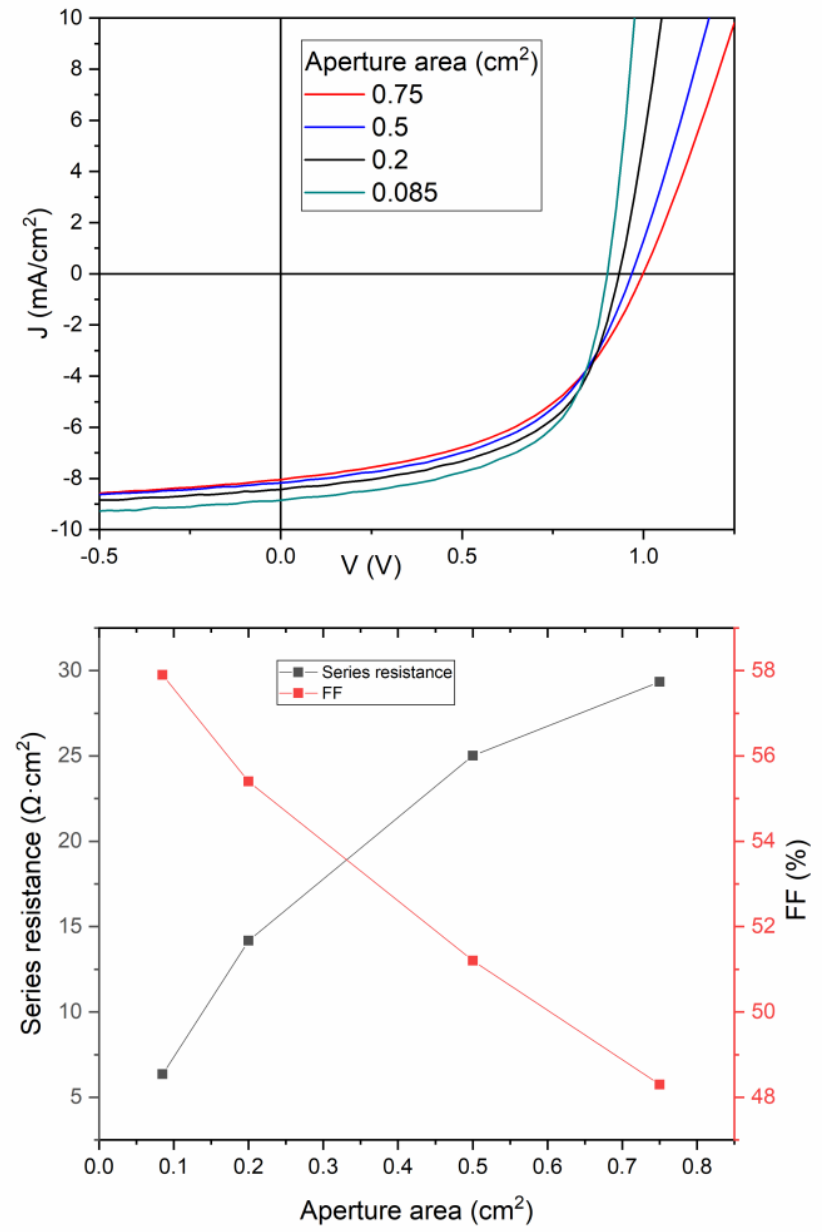

Fig. 7. J-V curves of an average device measured with different aperture areas using shadow masks (up). Effect of the aperture area over the series resistance of the devices. (down)

TABLE III

PV PARAMETERS OF AN AVERAGE DEVICE MEASURED WITH SHADOW MASKS WITH DIFFERENT APERTURE AREA.

\begin{tabular}{ccccc}
\hline \hline $\begin{array}{c}\mathrm{PV} \\
\text { Parameter }\end{array}$ & $0.75 \mathrm{~cm}^{2}$ & $0.50 \mathrm{~cm}^{2}$ & $0.2 \mathrm{~cm}^{2}$ & $0.085 \mathrm{~cm}^{2}$ \\
\hline$P C E(\%)$ & 3.88 & 4.04 & 4.32 & 4.60 \\
$F F(\%)$ & 48.3 & 51.2 & 55.4 & 57.9 \\
$J_{s c}$ & 8.04 & 8.18 & 8.43 & 8.85 \\
$\left(\mathrm{~mA} / \mathrm{cm}^{2}\right)$ & & & & \\
$R s$ & 29.34 & 25.01 & 14.17 & 6.35 \\
$(\Omega \cdot \mathrm{cm} 2)$ & 1.0 & 0.97 & 0.93 & 0.89 \\
$\mathrm{~V}_{\mathrm{oc}}(\mathrm{V})$ & & & &
\end{tabular}

The improved shape of the curves due to the better fill factor is evident when the smaller masks are used. This PCE change occurs even when a loss in $\mathrm{V}_{\mathrm{OC}}$ is occurring when using shadow masks, which can be associated with the dark diode at the periphery of the cell (electrically coupled to the illuminated area) [32].

We speculate that fabricating directly smaller slot-die coated areas would lead to higher PCE values than those obtained with shadow masks since for example the $\mathrm{V}_{\mathrm{OC}}$ would be slightly higher in that case. One of the advantages of small area devices is their low series resistance $\left(R_{s}\right)$. However, the fast increase in the overall $R_{s}$ needs to be considered when up scaling.

One of the main reasons for the low PCE in the large area solar cells can be related to its low FF, which is, at the same time, correlated with the $R_{s}$. $R_{s}$ is increased by an order of magnitude when going from the considered lab-scale areas $\left(0.085 \mathrm{~cm}^{2}\right)$ to larger area devices of $0.75 \mathrm{~cm}^{2}$. Therefore, the scalability lag of our devices would be greatly decreased when using optimized transparent electrodes with much lower sheet resistance [33]. The small $\mathbf{J}_{\mathrm{sc}}$ variations can be attributed to the need of selecting a spot in the whole area of the cell to place the aperture area, which leads to better-performing spots when the mask is placed.

\section{Stability}

All solar cells experienced a small decay in Jsc and FF after being stored in dark [34]. Fig. 8 shows the JV and EQE measured first after fabrication of the solar cells and then after 5 months of dark storage in a drawer. After 5 months the solar cells labelled 2 and 5 both show a PCE of 3.6\%, FF above $45 \%$ and Jsc of $6.5 \mathrm{~mA} / \mathrm{cm}^{2}$.

The reduction in current density and FF, the latter as result of increased Rs (from 28.1 to $33.3 \mathrm{ohms} / \mathrm{square}$ ), are the main causes of PCE reduction. The reduction in Jsc can in part be attributed to the yellowing of the epoxy glue used for encapsulation. The $\mathrm{V}_{\mathrm{OC}}$ remains the same after dark storage but quickly drops when continuously exposed to solar simulated light. The EQE of the solar cell labelled 5 does not show any big difference when measured after 5 months. The JV curve was measured prior to the EQE.

The integrated current density from the EQE after dark storage is $6.7 \mathrm{~mA} / \mathrm{cm}^{2}, 1.1 \mathrm{~mA} / \mathrm{cm} 2$ lower than the integrated current density from the fabrication day (Table I).

In contrast with the burn-in free process reported for PffBT4T:IDTBR solar cells [8], our devices with structure PET/ZnO/PffBT4T- ${ }_{9} \mathrm{C}_{13}: \mathrm{O}-\mathrm{IDTBR} / \mathrm{MoO} / \mathrm{Ag}$ encapsulated between two glass slides degrade $20 \%$ with respect to the initial value $\left(\mathrm{T}_{80}\right)$ in only $8.5,1.4$ and 5.8 hours in the cells coated respectively at $60^{\circ} \mathrm{C}, 80^{\circ} \mathrm{C}$ and $100^{\circ} \mathrm{C}$ (Fig. S10, SI). For all the coating temperatures under investigation, the drop of the Jsc was only about $8 \%$ after 110 hours. However, the Voc and the FF degraded much faster. For the device with active layer coated at $80^{\circ} \mathrm{C}$, the fast drop in PCE is directly related to the sharp drop in $\mathrm{V}_{\mathrm{OC}}$. It has been reported that the photo degradation of the $\mathrm{ZnO}$ electron transport layer results in a drop of the $\mathrm{V}_{\mathrm{OC}}[35]$. 

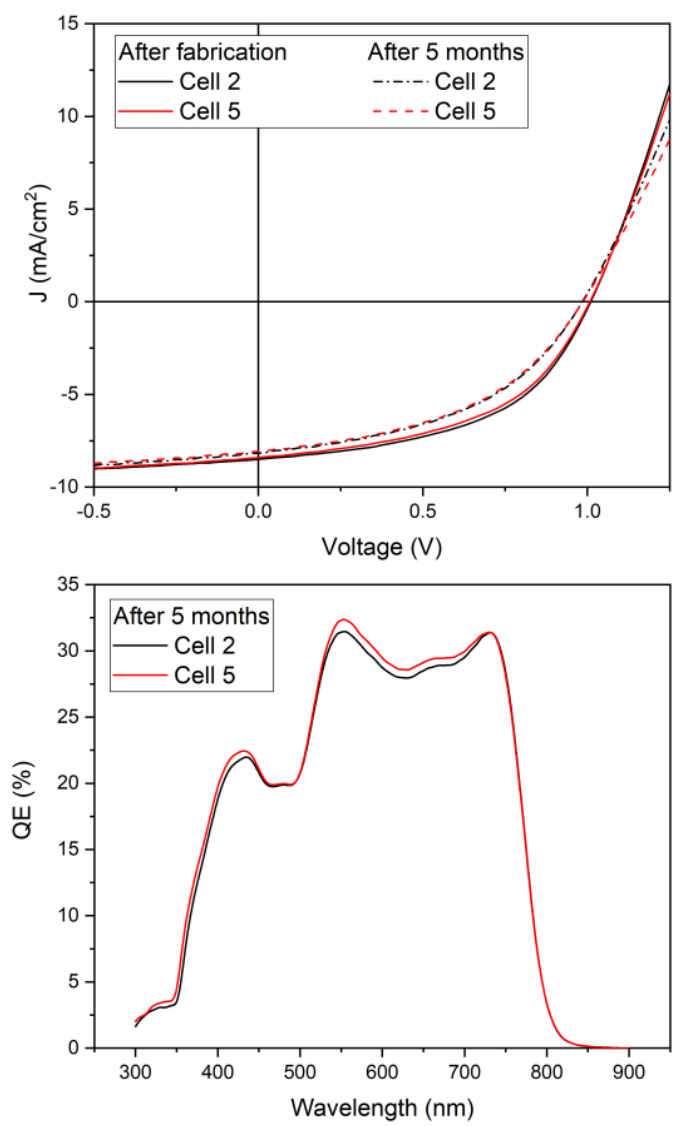

Fig. 8. JV and EQE measurements of a representative solar cell both coated at the optimum temperature of $80{ }^{\circ} \mathrm{C}$. The first measurement was taken the same day of the fabrication and encapsulation. The second measurement was taken after 5 months storage in a drawer at ambient temperature and humidity conditions.

The PffBT4T:IDTBR active layer has been chosen among the others for this study due to its high stability reported in literature; however, in our case the stability found for this material does not show any relevance. The main reason for the fast degradation suffered by the devices could be a result of coating in air at relatively high temperature, which means the active layer has been exposed to oxygen and humidity during the ink deposition and drying. In this study, the device coated at the lower temperature reports the longer $\mathrm{T}_{80}$. For the continuous illumination stability study in this work for $0,8 \mathrm{~cm}^{2}$ active area devices, we used a solar simulator, including the UV part of the spectrum which is a realistic approach to study the stability of organic solar cells devices [36]. It might explain in part the why the solar cells reported here degrade $20 \%$ in less than 10 hours compared with reports of similar active layer blends prepared by spin coating, aged under white LED arrays kept under $\mathrm{N}_{2}$ [5].

\section{CONCLUSIONS}

In this work, we demonstrate for the first time roll-processed flexible OSCs from PffBT4T-C $\mathrm{C}_{9} \mathrm{C}_{13}$ :O-IDTBR in open-air conditions by slot-die coating. It opens the possibility to utilize this method to fabricate solar cells, batteries, or transistors from materials suffering from Temperature Dependent Aggregation, thanks to the all-temperature controlled designed setup.
We also optimized deposition temperatures, ink flow, film thickness, and solution/additive combinations. The achieved efficiencies were up to $4.04 \%$ PCE for large-area devices, with open-circuit voltages above $1 \mathrm{~V}$. These efficiencies are still not close to the reported lab-scale efficiencies of PffBT4T:IDTBR devices, mainly due to the decreased FF caused by an increased series resistance of the flexible ITO substrate, and the low short current density of our devices. The active layer thickness limitation by our fabrication technique is also detrimental to the performance of our devices, increasing recombination losses. It is worth mentioning that to the best of our knowledge there are no other studies available at the time of this publication with the exact same active layer materials (PffBT4T- $\mathrm{C}_{9} \mathrm{C}_{13}$ : O-IDTBR). Moreover, we used only hydrocarbon solvents, which is a necessary condition to make this technology more industrially attractive. Fig. S11, SI shows the flexible substrate attached to the roll-coater. Fig. S12a, SI shows active layers on top of PET/ITO/ZnO flexible substrates, and Fig. S12b, SI shows the flexibility of the final devices.

Additionally, to the scalable deposition technique used, we demonstrate the possibility of producing OCSs on flexible substrates, a necessary condition to bridge the scalability lag of many OSCs under investigation nowadays.

We also demonstrate that there is still a big scalability lag for PffBT4T- $\mathrm{C}_{9} \mathrm{C}_{13}$ :O-IDTBR OSCs. The efficiency of an average device was $18.5 \%$ lower when comparing the full $0.75 \mathrm{~cm}^{2}$ device with measurements done with a $0.085 \mathrm{~cm}^{2}$ shadow mask. Most of the efficiency lost is attributed to the high series resistance large area cells, which can be partially attributed to the high sheet resistance of ITO in flexible substrates. Improving the transparent electrodes on PET is still a crucial step to overcome the scalability lag that is still present when moving to large-scale NFA solar cells in roll-to-roll fabrication.

Stability was also studied, and the devices showed excellent dark-storage stability after five months. However, the stability under a solar simulator was poor, and the devices showed a clear burn-in effect that was not occurring in previously reported studies for lab-scale devices based on a similar active layer.

Several steps need to be addressed in order to move forward the scalability of the system: increase the current density of our devices, studying the reasons of this current losses when upscaling; improve the stability by developing solutions to improve the photostability of the active layer; and scale up to module-level with areas larger than $10 \mathrm{~cm}^{2}$.

\section{ACKNOWLEDGMENTS}

We gratefully acknowledge funding from the European Research Council (ERC) under the European Union's Horizon 2020 research and innovation programme (SEEWHI - Solar Energy Enabled for the World by High Resolution Imaging, Consolidator Grant No. 681881).

We thank Kristian Larsen for all the technical help that made possible to carry out this scientific publication.

Special acknowledgement to Tomas Hugh Youngman (DTU Physics) for conducting the Spectroscopic Ellipsometry measurements, necessary to have a precise $\mathrm{MoO}_{3} \mathrm{HTL}$ in our devices. 


\section{REFERENCES}

[1] M. Zhang et al., "Single-layered organic photovoltaics with double cascading charge transport pathways: 18\% efficiencies," Nat. Commun., vol. 12, no. 1, p. 309, 2021.

[2] N. Espinosa, M. Hösel, D. Angmo, and F. C. Krebs, "Solar cells with one-day energy payback for the factories of the future," Energy Environ. Sci., vol. 5, pp. 5117-5132, 2012.

[3] A. S. Gertsen, M. Fernandez Castro, R. R. Søndergaard, and J. W. Andreasen, "Scalable fabrication of organic solar cells based on non-fullerene acceptors," Flex. Print. Electron., vol. 5, p. 014004, 2019.

[4] S. Holliday et al., "High-efficiency and air-stable P3HT-based polymer solar cells with a new non-fullerene acceptor," Nat. Commun., vol. 7, p. 11585, 2016.

[5] A. Wadsworth et al., "Highly Efficient and Reproducible Nonfullerene Solar Cells from Hydrocarbon Solvents," ACS Energy Lett., vol. 2, no. 7, pp. 1494-1500, 2017.

[6] G. Zhang et al., "Overcoming Space-Charge Effect for Efficient Thick-Film Non-Fullerene Organic Solar Cells," Adv. Energy Mater., vol. 8, no. 25, p. 1801609, 2018.

[7] D. Baran et al., "Reduced voltage losses yield $10 \%$ efficient fullerene free organic solar cells with $>1 \mathrm{~V}$ open circuit voltages," Energy Environ. Sci., vol. 9, no. 12, pp. 3783-3793, 2016.

[8] H. Cha et al., "An Efficient, 'Burn in' Free Organic Solar Cell Employing a Nonfullerene Electron Acceptor," Adv. Mater., vol. 29, no. 33, p. 1701156, 2017.

[9] S. Strohm et al., "P3HT: Non-fullerene acceptor based large area, semi-transparent PV modules with power conversion efficiencies of 5\%, processed by industrially scalable methods," Energy Environ. Sci., vol. 11, no. 8, pp. 2225-2234, 2018.

[10] M. Fernández Castro, E. Mazzolini, R. R. Sondergaard, M. Espindola-Rodriguez, and J. W. Andreasen, "Flexible ITO-Free Roll-Processed Large-Area Nonfullerene Organic Solar Cells Based on P3HT:O-IDTBR," Phys. Rev. Appl., vol. 14, no. 3, p. 034067, 2020.

[11] I. Pelse, A. L. Jones, L. J. Richter, and J. R. Reynolds, "Probing Crystallization Effects when Processing Bulk-Heterojunction Active Layers: Comparing Fullerene and Nonfullerene Acceptors," Chem. Mater., vol. 33, no. 2, pp. 657-667, 2021.

[12] K. Yu, S. Rich, S. Lee, K. Fukuda, T. Yokota, and T. Someya, "Organic Photovoltaics: Toward Self-Powered Wearable Electronics," Proc. IEEE, vol. 107, no. 10, pp. 2137-2154, 2019.

[13] H. Hu, P. C. Y. Chow, G. Zhang, T. Ma, J. Liu, and G. Yang, "Design of Donor Polymers with Strong Temperature-Dependent Aggregation Property for Efficient Organic Photovoltaics," Acc. Chem. Res., vol. 50, pp. 2519-2528, 2017.

[14] H. Zhao et al., "Hot Hydrocarbon-Solvent Slot-Die Coating Enables High-Efficiency Organic Solar Cells with Temperature-Dependent Aggregation Behavior," Adv. Mater., vol. 32, no. 39, p. 2002302, 2020.

[15] B. Park, I. G. Bae, O. E. Kwon, and H. G. Jeon, "Organic thin-film transistors fabricated using a slot-die-coating process and related sensing applications," RSC Adv., vol. 6, no. 103, pp. 101613 101621, 2016.

[16] Z. Lin et al., "Solution-processed high performance organic thin film transistors enabled by roll-to-roll slot die coating technique," Org. Electron., vol. 54, no. December 2017, pp. 80-88, 2018.

[17] J. Zhao et al., "Efficient organic solar cells processed from hydrocarbon solvents," Nat. Energy, vol. 1, p. 15027, 2016.

[18] M. J. Griffith et al., "Combining Printing, Coating, and Vacuum Deposition on the Roll-to-Roll Scale: A Hybrid Organic Photovoltaics Fabrication," IEEE J. Sel. Top. Quantum Electron., vol. 22, no. 1, pp. 112-125, 2016.

[19] H. You, L. Dai, Q. Zhang, D. Chen, Q. Jiang, and C. Zhang, "Enhanced performance of inverted non-fullerene organic solar cells by using metal oxide electronand hole-selective layers with process temperature $\leq 150{ }^{\circ} \mathrm{C}$, Polymers (Basel)., vol. 10, no. 7, p. 725, 2018.

[20] J. Meyer, A. Shu, M. Kröger, and A. Kahn, "Effect of contamination on the electronic structure and hole-injection properties of $\mathrm{MoO} 3$ /organic semiconductor interfaces," Appl. Phys. Lett., vol. 96, no. 13, p. 133308, 2010.

[21] F. Zhao, C. Wang, and X. Zhan, "Morphology Control in Organic Solar Cells," Adv. Energy Mater., vol. 8, no. 28, p. 1703147, 2018.
[22] R. S. Gurney, D. G. Lidzey, and T. Wang, "A review of nonfullerene polymer solar cells: From device physics to morphology control," Reports Prog. Phys., vol. 82, no. 3, p. 036601, 2019.

[23] B. Xue et al., "Vertical stratification and interfacial structure in P3HT:PCBM Organic solar cells," J. Phys. Chem. C, vol. 114, no. 37, pp. 15797-15805, 2010.

[24] J. A. Bartelt, D. Lam, T. M. Burke, S. M. Sweetnam, and M. D. McGehee, "Charge-Carrier Mobility Requirements for Bulk Heterojunction Solar Cells with High Fill Factor and External Quantum Efficiency $>90 \%$," Adv. Energy Mater., vol. 5, no. 15, p. 1500577, 2015.

[25] R. Søndergaard, M. Hösel, D. Angmo, T. T. Larsen-Olsen, and F. C. Krebs, "Roll-to-roll fabrication of polymer solar cells," Mater. Today, vol. 15, no. 1-2, pp. 36-49, 2012.

[26] L. Ma et al., "High-Efficiency Nonfullerene Organic Solar Cells Enabled by $1000 \mathrm{~nm}$ Thick Active Layers with a Low Trap-State Density," ACS Appl. Mater. Interfaces, vol. 12, no. 16, pp. 1877718784, 2020.

[27] S. R. Cowan, A. Roy, and A. J. Heeger, "Recombination in polymer-fullerene bulk heterojunction solar cells," Phys. Rev. B Condens. Matter Mater. Phys., vol. 82, no. 24, p. 245207, 2010.

[28] A. K. K. Kyaw et al., "Intensity Dependence of Current-Voltage Characteristics and Recombination in High-Efficiency SolutionProcessed Small-Molecule Solar Cells," ACS Nano, vol. 7, no. 5, pp. 4569-4577, 2013.

[29] A. K. K. Kyaw et al., "Effects of solvent additives on morphology, charge generation, transport, and recombination in solutionprocessed small-molecule solar cells," Adv. Energy Mater., vol. 4, no. 7, p. 1301469, 2014.

[30] Z. Hamid et al., "Influence of Polymer Aggregation and Liquid Immiscibility on Morphology Tuning by Varying Composition in PffBT4T-2DT/Nonfullerene Organic Solar Cells," Adv. Energy Mater., vol. 10, no. 8, p. 1903248, 2020.

[31] Y. Wang et al., "Optical Gaps of Organic Solar Cells as a Reference for Comparing Voltage Losses," Adv. Energy Mater., vol. 8, no. 28, p. 1801352, 2018.

[32] M. Despeisse, R. Gogolin, D. Zielke, and I. Andri, "Demonstrating the high Voc potential of PEDOT : PSS / c-Si heterojunctions on on solar cells," Energy Procedia, vol. 124, pp. 593-597, 2017.

[33] Z. Wang et al., "High Power Conversion Efficiency of $13.61 \%$ for 1 $\mathrm{cm} 2$ Flexible Polymer Solar Cells Based on Patternable and MassProducible Gravure-Printed Silver Nanowire Electrodes," $A d v$. Funct. Mater., vol. 31, no. 4, p. 2007276, 2021.

[34] C. H. Peters, I. T. Sachs-Quintana, J. P. Kastrop, S. Beaupré, M. Leclerc, and M. D. McGehee, "High Efficiency Polymer Solar Cells with Long Operating Lifetimes," Adv. Energy Mater., vol. 1, no. 4, pp. 491-494, Jul. 2011

[35] Z. Kam, X. Wang, J. Zhang, and J. Wu, "Elimination of Burn-in Open-Circuit Voltage Degradation by ZnO Surface Modification in Organic Solar Cells," ACS Appl. Mater. Interfaces, vol. 7, no. 3, pp. 1608-1615, Jan. 2015.

[36] M. O. Reese et al., "Consensus stability testing protocols for organic photovoltaic materials and devices," Sol. Energy Mater. Sol. Cells, vol. 95, no. 5, pp. 1253-1267, 2011. 


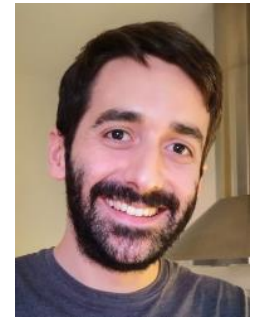

Marcial Fernández Castro was born in Vigo, Galicia, Spain in 1991. He received the B.S degree in Physics from the University of Santiago de Compostela in 2014. He received a M.S. degree in Energy and Sustainability from the Universidade de Vigo and a M.S. degree in Material Science from the Universidad de Sevilla (2016). He worked for one year as research assistant at IMN-CSIC in Madrid, co-authoring three peer-reviewed publications. Marcial Fernández started his $\mathrm{PhD}$ studies at Technical University of Denmark in 2018, and this work was submitted during his studies.

His $\mathrm{PhD}$ project is focused on roll-processing of Organic Solar Cells, with the main aim of helping with the upscaling issues that the technology suffers, in order to overcome the scalability lag. This is the second publication as main author that is part of his $\mathrm{PhD}$ studies.

Moisés Espíndola Rodríguez Moises Espindola Rodriguez was born in México City, México in 1986. He graduated as M. Sc. in Physico-Mathematical Sciences from the National Polytechnic Institute (IPN), México in 2011 and received his Ph.D. from Barcelona University, Spain in 2015. He is currently postdoc researcher at the Technical University of Denmark, Department of Energy Conversion and Storage, and has previously worked as postdoc at the Catalan Institute for Energy Research, Spain. he has authored or co-authored 52 peerreviewed papers in international journals. His research interests include electrodes, hole and electron transport layers for the fabrication of opaque, bifacial and semitransparent organic and inorganic photovoltaic solar cells.

Dr. Espindola-Rodriguez is member of the Mexican Society of Science and Technology of Surfaces and Materials A.C.

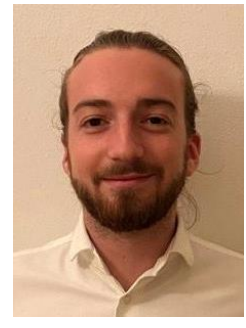

Edoardo Stanzani was born in Cento (FE), Italy in 1996. He received a bachelor's degree in mechanical engineering from the University of Modena and Reggio Emilia (Italy) in 2019. He is studying his M.Sc. in Materials Engineering and Nanotechnology in Politecnico di Milano (Italy) and he is currently working as external researcher in the Technical University of Denmark in the Department of Energy Conversion and Storage.

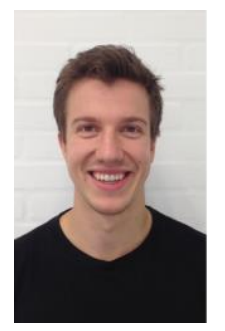

Michael Korning Sørensen was born in Copenhagen, Denmark in 1991. He received the B.S degree in Physics and Nanotechnology from the Technical University of Denmark in 2016. He received a M.S. degree in Physics and Nanotechnology with specialty in condensed matter physics and neutron imaging from the Technical University of Denmark Michael K. Sørensen started his PhD studies in 2018 working on a Ph.D. project devoted to developing methods to probe and analyze the morphology evolution of organic solar cells as they are fabricated.

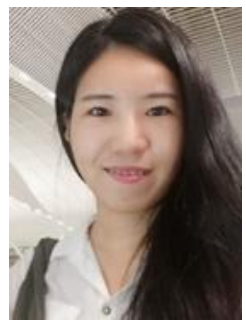

Shinhee Yun was born in South Korea in 1989. She received a Ph.D. degree in the Department of Physics, Korea Advanced Institute of Science and Technology in 2020. In the same year, she joined the Functional Oxide laboratory in the Department of Energy Conversion and Storage, Technical University of Denmark as a post-doctor. Her current research topic is oxide functional devices using flexoelectricity.

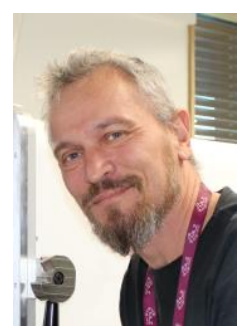

Jens Wenzel Andreasen (corresponding author) was born in Copenhagen, Denmark in 1969. He graduated as M.Sc. in geology from University of Copenhagen in 2000 and received his $\mathrm{PhD}$ degree in chemistry from the Technical University of Denmark in 2005.

He is currently Professor at the Technical University of Denmark, Department of Energy Conversion and Storage and has previously worked as Senior Researcher at the Risø National Laboratory for Sustainable Energy in Roskilde, Denmark. He has authored or co-authored 111 peer-reviewed papers in international journals and one book-chapter in Conjugated Polymers and Oligomers: Structural and Soft Matter Aspects. Knaapila, M. (ed.). World Scientific, p. 159174 (Materials and Energy, Vol. 9), 2017. His research interests include the atomic to mesoscale structure of materials for sustainable energy as well as their dynamical coupling to electronic structure.

Prof. Andreasen is a member of the International Union of Crystallography and the American Crystallographic Association. He holds a Consolidator Grant from the European Research Council (ERC). 